\title{
HYBRID POSITION CONTROLLER FOR AN INDIRECT FIELD-ORIENTED INDUCTION MOTOR DRIVE
}

\author{
Antonio B. de Souza Junior ${ }^{1}$, Tobias R. Fernandes Neto ${ }^{1}$, Dalton de A. Honório ${ }^{1}$, Eber de C. Diniz ${ }^{2}$, \\ Luiz H. S. C. Barreto ${ }^{1}$, Laurinda L. N. dos Reis ${ }^{1}$ \\ Robotic and Automation Research Group - (GPAR) of Federal University of Ceará, Fortaleza - CE, Brasil ${ }^{1}$ \\ Federal University of Ceará, Sobral - CE, Brasil ${ }^{2}$ \\ e-mails: \{barbosa, tobias, dalton, eber, lbarreto, laurinda\}@dee.ufc.br
}

\begin{abstract}
This paper presents the study and implementation of a hybrid position controller for an indirect field-oriented induction motor drive. In order to improve the position tracking performance of an induction motor drive, a design procedure of a hybrid controller is developed based on the conventional Proportional (P) controller and the Generalized Predictive Control (GPC) controller. The fuzzy logic is utilized to achieve the hybridization between the $P$ and GPC controllers. The $P$ is adopted because its parameter values can be simple chosen with an aggressive tuning (fast response), while the GPC controller enhances the robustness and has a moderate controller action. Then, the position control loop is regulated with the hybrid controller, while the speed and currents loops incorporate PI (Proportional Integral) controllers. The proposed controller, simulations, implementation data, and test results with step, trapezoidal, triangular position profiles and step change in load, are given, discussed and verified. It is shown that the proposed position hybrid controller has a fast tracking capability to industrial robotics applications and it is robust to load disturbance.
\end{abstract}

Keywords-Field-Oriented Control, Fuzzy Logic, Hybrid Control, Predictive Control.

\section{INTRODUCTION}

Nowadays, the industry automation is the key technology in factory automation, thus the motion control plays a big role in high precision applications. The Induction Machines (IM) are widely used in the industry due to simplicity, lower cost, reduced need for maintenance and greater robustness, if compared to other types of electrical machines. The main issue of using the IM as a high-precision servo motor drive is its non-linear mathematical model and the parametric uncertainties, e.g. load, rotor resistance and inductance. Typically, the position control of the motor shaft is performed by employing direct current (DC) motors or permanent magnets synchronous motor [1]. In general, the two basic performance requirements for every motor drive are: high disturbance rejection and fast tracking set-point without overshoot [2].

In the last two decades, advances have occurred in the study of principles that govern the field-oriented control applied to alternating current (AC) machines. Therefore, the control of induction machines could achieve performances similar to DC motors. The machine currents and voltages

Manuscript received 31/03/2014; revised 23/06/2014; accepted for publication 11/11/2014, by recommendation of the Regular Section Editor Cassiano Rech. using the field-oriented control allow the direct control of the spatial orientation of the electromagnetic fields, resulting in the use of the term field-oriented for this type of controller. In this type of control, a direct analogy can be established with the control of a separately excited DC motor [1].

Studies of current controllers applied in the IM are very widespread, having distinct approaches as could be seem in the following works. [3] proposes a Fuzzy Logic Current Controller (FLCC) applied to the IM. A robust current controller based in linear matrix inequality used in a DoublyFed Induction Generator (DFIG) is reported in [4], and, with variable structure control (VSC) aproach, [5] proposes a sliding mode controller (SMC) for the IM current loop applied to robotic arm applications.

In speed loop applications for IM drives, several studies presented predictive control strategies in order to modelling the loop dynamics, for instance [6]. A sensorless adaptive speed estimation which uses the strategy named Model Reference Adaptive Control (MRAC) is presented in [7]. Additionally, a nonlinear model predictive controller is used in the speed tracking of a linear induction machine [8].

Recently, structures mixing various types of controllers known as hybrid controllers have been proposed by several researchers in order to achieve the best performance for each strategy. In [9], a hybrid PID controller is presented, which has the advantage of being easily tuned by a fuzzy controller, improving the system robustness. A new robust MRAC using a hybrid strategy is proposed in [10].

In order to precisely control the shaft position in IMs with encoder sensor, a proper strategy is necessary. A design method based on the internal model control (IMC) theory was developed in [2] to achieve a high-performance motion control of a IM. Moreover, a variable structure control (VSC) with adaptive gain is used in the speed loop for the IM positioning [11]. In [12], a robust position controller with the fuzzy logic control is described.

Therefore, this paper deals with the design of a hybrid controller which acts on the position control loop, in order to achieve the best position tracking performance of the IM shaft. At first, a conventional P controller with fixed gain was tuned, where fast changes in the position reference are considered. Then, a GPC controller is proposed to increase the robustness of the control. However, additional time is necessary to reach the shaft position reference, if compared with the P controller.

In order to take de advantage of the properties of both controllers, the fuzzy logic was used to combine the $\mathrm{P}$ 


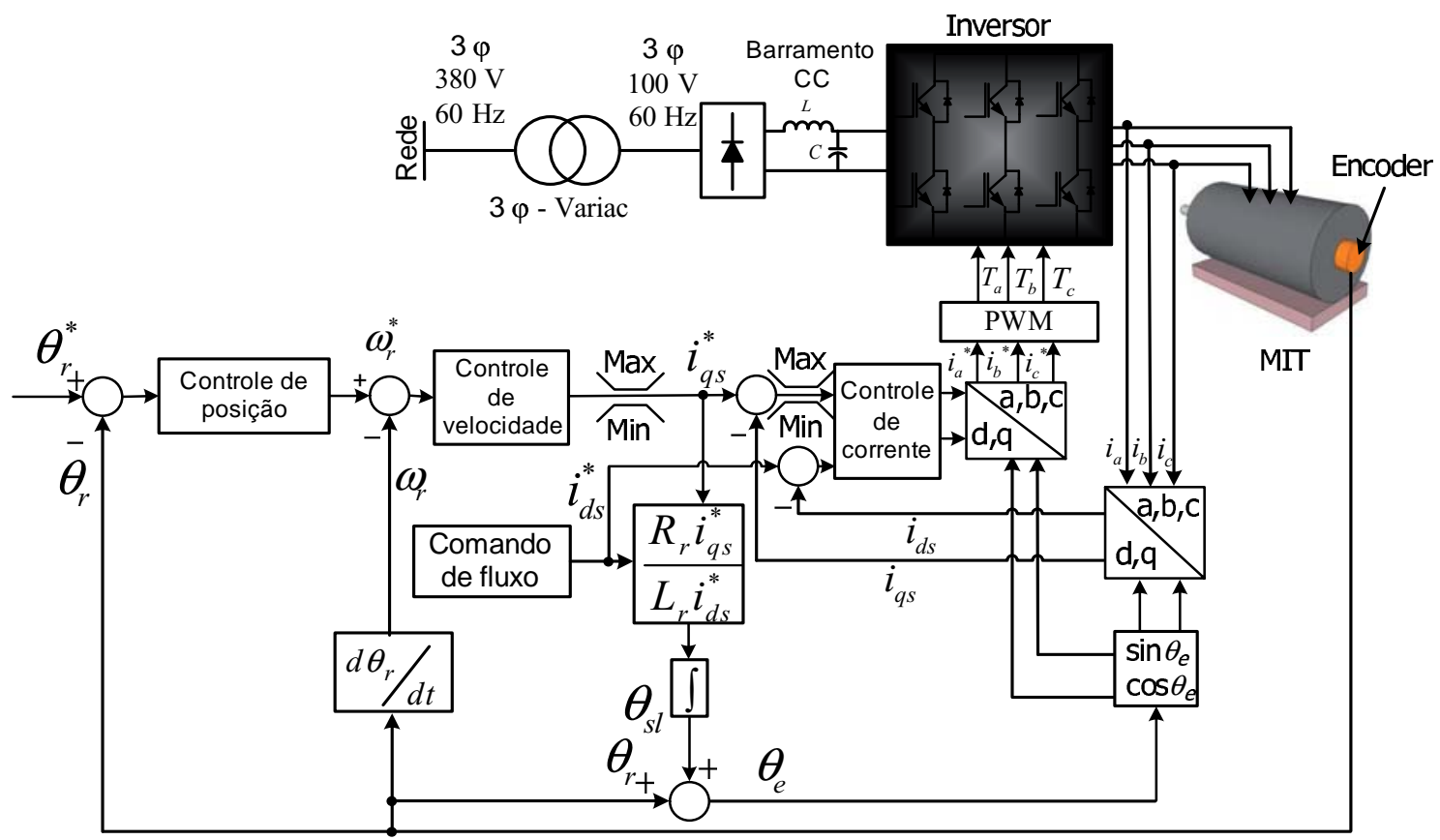

Fig. 1. Block diagram representing the field-oriented induction motor drive with proposed hybrid position controller mixed with the classical speed and current controllers.

and GPC controllers for a robust and fast position tracking performance under load torque disturbances.

The technologic contribution of this study lies in the possible applications to robotics, i.e., the use of IMs in the joint of a robot arm. The main scientific contribution consists in the study of a hybrid control that mixes the advantages of two control techniques well known in literature, in this case the $\mathrm{P}$ and GPC controllers.

Finally, this work presents simulations tests and experimental results in order to demonstrate the main features of the developed system, thus validating the employed methodology. The paper is organized as follows. Section II describes the mathematical model of the decoupled IM. The conventional $\mathrm{P}$ and GPC controllers design are presented in Section III. Section IV presents the experimental implementation. Simulation and experimental verifications are also included in this section. Finally, the conclusions are given in section V.

\section{MOTOR MODEL}

The block diagram of the indirect field-oriented induction motor drive is shown in Figure 1.

The state equations of the induction motor in the rotating dq- reference frame are given as follows [1]:

$$
\dot{x}=\mathrm{A} x+\mathrm{B} u
$$

where:

$$
x=\left[\begin{array}{c}
i_{d s} \\
i_{q s} \\
\lambda_{d r} \\
\lambda_{q r}
\end{array}\right] ; \quad \mathrm{Bu}=\frac{1}{\sigma L_{s}}\left[\begin{array}{l}
v_{d s} \\
v_{q s} \\
0 \\
0
\end{array}\right]
$$

$$
\mathrm{A}=\left[\begin{array}{cccc}
\frac{R_{s}}{\sigma L_{s}}-\frac{R_{r}(1-\sigma)}{\sigma L_{r}} & \omega_{e} & \frac{L_{m} R_{r}}{\sigma L_{s} L_{r}{ }^{2}} & \frac{P \omega_{r} L_{m}}{2 \sigma L_{s} L_{r}{ }^{2}} \\
\omega_{e} & -\frac{R_{s}}{\sigma L_{s}}-\frac{R_{r}(1-\sigma)}{\sigma L_{r}} & \frac{-P \omega_{r} L_{m}}{2 \sigma L_{s} L_{r}{ }^{2}} & \frac{L_{m} R_{r}}{\sigma L_{s} L_{r}{ }^{2}} \\
\frac{L_{m} R_{r}}{L_{r}} & 0 & -\frac{R_{r}}{L_{r}} & \omega_{e}-\frac{P}{2} \omega_{r} \\
0 & \frac{L_{m} R_{r}}{L_{r}} & -\left(\omega_{e}-\frac{P}{2} \omega_{r}\right) & -\frac{R_{r}}{L_{r}}
\end{array}\right] .
$$

The torque is given by:

$$
T_{e}=\frac{3 P}{4} \frac{L_{m}}{L_{r}}\left(i_{q s} \lambda_{d r}-i_{d s} \lambda_{q r}\right)
$$

where,

$T_{e} \quad$ - Electromagnetic torque;

$R_{s} \quad$ - Stator resistance per phase;

$L_{s} \quad$ - Stator self inductance per phase;

$R_{r} \quad$ - Rotor resistance per phase;

$L_{r} \quad$ - Rotor self inductance per phase;

$L_{m} \quad$ - Magnetizing inductance per phase;

$P$ - Number of poles;

$\omega_{e} \quad$ - Electrical angular speed;

$\omega_{s}$ - Slip angular speed;

$v_{d s} \quad-\quad \mathrm{d}$-axis stator voltage;

$v_{q s} \quad$ - q-axis stator voltage;

$i_{d s} \quad$ - d-axis stator current;

$i_{q s} \quad$ - q-axis stator current.

In addition,(3)-(5) give the following parameters:

$$
\sigma=1-\frac{L_{m}{ }^{2}}{L_{s} L_{r}},
$$




$$
\begin{aligned}
& \lambda_{q r}=L_{m} i_{q s}+L_{r} i_{d r}, \\
& \lambda_{d r}=L_{m} i_{d s}+L_{r} i_{q r} .
\end{aligned}
$$

In ideally field-oriented technique, the decoupling between $\mathrm{d}$ and q-axis can be achieved, when the rotor flux linkage is forced to align with the d-axis. Then, the flux linkage and its derivative in the q-axis are set to zero as:

$$
\lambda_{q r}=0 \text { and } \frac{d \lambda_{q r}}{d t}=0 .
$$

Then, from (1) the stator voltage equations are given by equations (7) and (8), then:

$$
\begin{gathered}
v_{q s}=\left(R_{s}+L_{s}^{\prime} s\right) i_{q s}+\omega_{e} L_{s} i_{d s} \\
v_{d s}=r_{s} i_{d s}-\omega_{e} L_{s}^{\prime} i_{q s}
\end{gathered}
$$

where:

$$
L_{s}^{\prime}=L_{s}-\frac{L_{m}^{2}}{L_{r}}
$$

The rotor flux linkage can be found from the third row in (1) and by using (3) as:

$$
\lambda_{d r}=\frac{L_{m} i_{d s}}{1+s \frac{L_{r}}{R_{r}}} .
$$

The stator current changes with a short time constant, if it is compared with the mechanical system time constant, thus the latter is assumed as negligible. During the operation, the amplitude of the rotor flux linkage is generally held constant $i_{d s}=i_{d s}^{*}$. Then, the rotor flux linkage from (10) becomes:

$$
\lambda_{d r}=L_{m} i_{d s}^{*} .
$$

Finally, using (6) and (11) into (2), the electromagnetic torque can be rewritten as follows:

$$
T_{e}=\frac{3 P}{4} \frac{L_{m}^{2}}{L_{r}} i_{q s}^{*} i_{d s}^{*}
$$

where $i_{q s}^{*}$ denotes the torque current command generated from the torque controller $G_{c}(s)$.

The slip angular speed is necessary to calculate the rotor angular position. Substituting (4) and (10) into the fourth row of (1), and considering that the rotor flux linkage is kept constant, the slip angular speed is obtained, thus:

$$
\omega_{s l}=\frac{L_{m} R_{r} i_{q s}^{*}}{L_{r} \lambda_{d r}}=\frac{R_{r} i_{q s}^{*}}{L_{r} i_{d s}^{*}} .
$$

Once the slip angular speed is determined, the rotor flux linkage position is equal to:

$$
\theta_{e}=\theta_{r}+\underbrace{\int \frac{R_{r} i_{q s}^{*}}{L_{r} i_{d s}^{*}} d t}_{\theta_{s l}} .
$$

As the rotor mechanical position $\theta_{r}$ is converted by the encoder, the slip angle $\theta_{s l}$ is determined using (14).

\section{CONTROLLERS DESIGN}

\section{A. Systems Modelling}

The transfer function of a given system can be found by using several identification methods. The well-known approaches used to identify a closed-loop real industrial process (see Figure 2) are the relay and Ziegler-Nichols methods [13], and Yuwana and Seborgś method [14].

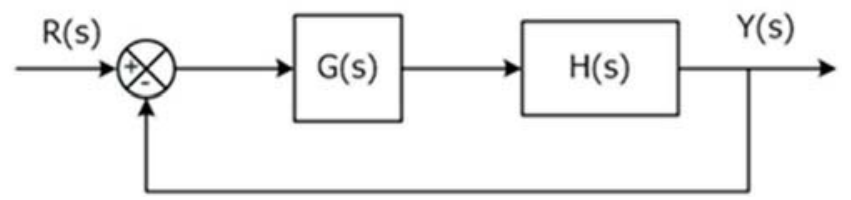

Fig. 2. Configuration structure of a closed loop system for the aforementioned identification methods.

The large majority of industrial process units to be controlled can be adequately approximated by a first-order plus time delay (FOPTD) model [15] and it is given by:

$$
H(s)=\frac{K e^{-\tau_{d} s}}{1+\tau s}
$$

where:

$K$ - Gain of the process model;

$\tau$ - Time constant of the FOPTD process model;

$\tau_{d}$ - Time delay.

As the time delay is the sampling time $(0.1 \mathrm{~ms})$, the parameter $\tau_{d}$ will be neglected. Considering that the aforementioned parameters for $\mathrm{H}(s)$ are properly determined by by the following expressions [15]:

$$
\begin{gathered}
K=\frac{y_{\infty}}{K_{c}\left(A-y_{\infty}\right)}, \\
y_{\infty} \approx \frac{y_{p 2} y_{p 1}-y_{m}^{2}}{y_{p 2}+y_{p 1}-2 y_{m}}, \\
K_{f}=K_{c} K, \\
+\frac{\Delta t \sqrt{\left(1-\zeta^{2}\right)\left(K_{f}+1\right)}}{\pi} \sqrt{\zeta^{2}\left(K_{f}+1\right)+K_{f}} \\
\zeta_{1}=\frac{-\ln \left[\frac{y_{\infty}-y_{m}}{\left.y_{p 1}-y_{\infty}\right]}\right.}{\sqrt{\pi^{2}+\left(\ln \left[\frac{y_{\infty}-y_{m}}{y_{p 1}-y_{\infty}}\right]\right)^{2}}}, \\
\zeta_{2}=\frac{-\ln \left[\frac{y_{p 2}-y_{\infty}}{y_{p 1}-y_{\infty}}\right]}{\sqrt{4 \pi^{2}+\left(\ln \left[\frac{y_{p 2}-y_{\infty}}{y_{p 1}-y_{\infty}}\right]\right)^{2}}} .
\end{gathered}
$$

The variable $\zeta$ in (19) is the mean value mean value of the values computed from (20) and (21). One can use the Yawana and Seborg's identification method, that apply the step response to obtain the model. Figure 3 shows the position step response for the proposed IM drive system. Therefore, the parameters for the Yawana and MATLAB ${ }^{\mathrm{TM}}$ 's 
identification method are found by using this figure. i.e. $y_{p 1}=1.1 ; y_{p 2}=1.01 ; K_{c}=5 ; y_{m}=0.96 ; A=1$; $\Delta t=0.06 ; y_{\infty}=0.9968 ; K=63.13 ; K_{f}=315.67$; $q$ si $=0.282 ; \tau=7.7569$.

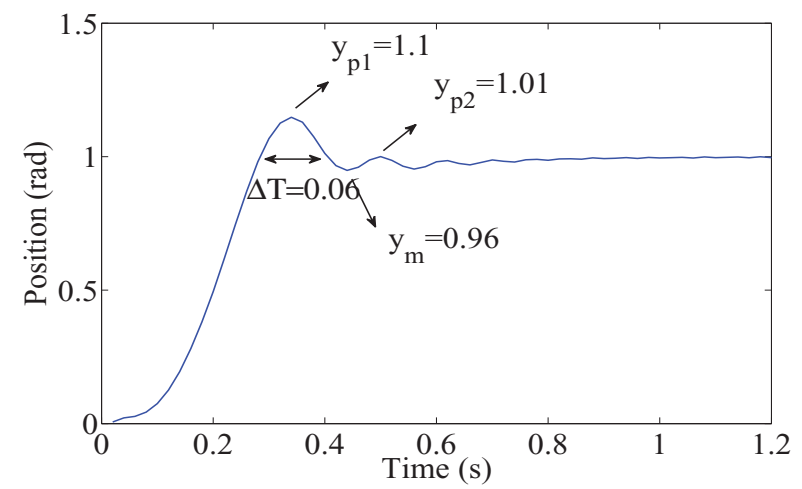

Fig. 3. Step response in the time domain using the Yawana and Seborg identification method.

By using (15) and the found parameters, the equivalent open loop transfer function in continuous-time for the position loop is obtained as:

$$
H(s)=\frac{63.13}{7.757 s+1}
$$

The transfer function in discrete-time by assuming a sampling rate of $0.1 \mathrm{~ms}$ and using a zero-order-hold equivalent system is given by:

$$
H(z)=\frac{0.0008139 z^{-1}}{1-z^{-1}}
$$

This model presents a integral with a gain which facilities the implementation of the propose controller.

\section{B. Proportional Position Controller Design}

There are several methods for tuning PID controllers with fixed gain that are used in the industry with great success rate. The Ziegler-Nichols method in [16] is adopted for designing a PID controller because its design rule is simple and systematic.

Generally, the classical literature uses a PI controller structure for the current and speed control loops, while a simple P-type controller is employed in the position control loop. The step response of the obtained transfer function model (23) is shown in Figure. 4. Figure. 4 shows the step response from the Ziegler-Nichols method [16], as result, it is possible to determine the parameter $K p=0.65477$ for the position controller. The other parameters of the current and speed controllers were calculated in [5], where was used to these loops the modified Ziegler Nichols method. The parameters of the current controller were $K_{c}=44.5$ and $T_{i}=$ $5.6 \mathrm{~ms}$ and for the speed controller were $K_{c}=3.7$ and $T_{i}=$ $13.52 \mathrm{~ms}$.

\section{Generalized Predictive Controller Design}

For the implementation of the predictive controller, it is necessary to compute the process prediction horizon, and then it requires a preliminary study to determine a time-series

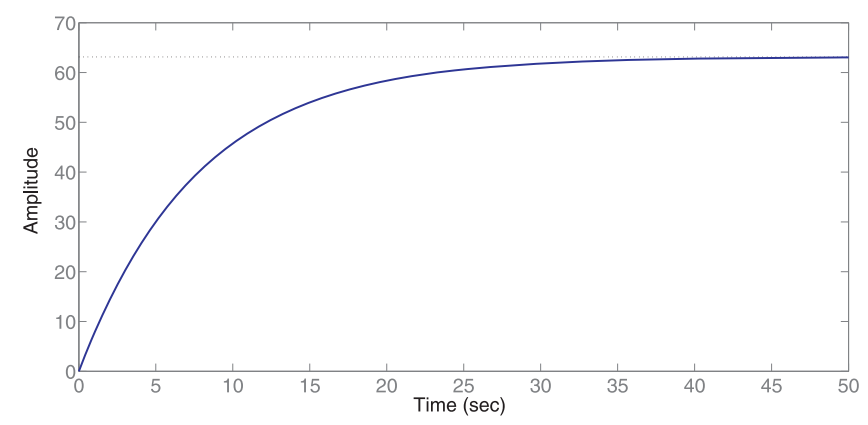

Fig. 4. Step response in the time domain of the system in open loop condition.

structure that best matches the system. Thus, this section describes the time-series modelling for the system and the predictive controller.

1) GPC-Based I+P controller design - A predictive strategy first requires the definition of a time-series model. A commonly used model is the CARIMA (Controlled Auto Regressive and Integrated Moving Average model) [17]:

$$
A\left(z^{-1}\right) y(k)=z^{-d} B\left(z^{-1}\right) u(k)+\frac{C\left(z^{-1}\right)}{\Delta} \xi(k),
$$

where $A, B$ and $C$ are polynomials in the backward shift operator $z^{-1}$ (that will be omitted in the following equations) corresponding to the plant output, the control input and the systems noise. The polynomial $A$ is monic and coprime in relation to $B, d$ represents the system delay in samples of time, while $\xi(k)$ is an uncorrelated zero mean random sequence, $\Delta$ denotes the differencing operator defined by $\Delta=1-z^{-1}$, $u(k)$ is the input and $y(k)$ is the output signal. From (24), we can find the correspondent polynomials of (25): $A\left(z^{-1}\right)=1-z^{-1}, B\left(z^{-1}\right)=0.0008139 z^{-1}, C\left(z^{-1}\right)=1$.

The I $+\mathrm{P}$ control schemes have been widely used in industrial process. All the controllers uses RST structure presented in [16], as show in Figure 5, where $y_{r}(k)$ is reference, $u(k)$ control input, and $y(k)$ output of process, $d_{\text {in }}(k)$ and $d_{\text {out }}(k)$ are perturbations of input and output, respectively and $\eta(k)$ is a noise.

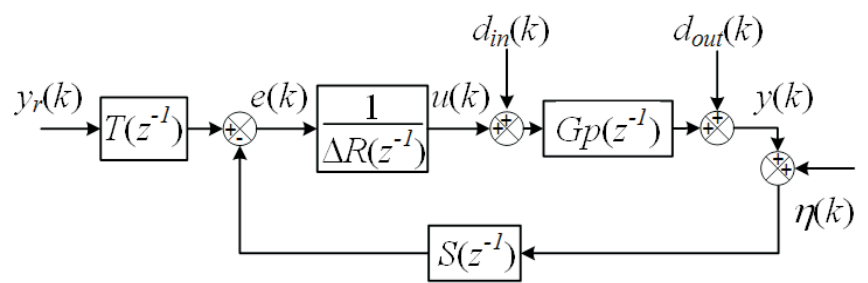

Fig. 5. RST predictive controller structure used in the design procedure.

From Figure 5 the controller structure is given by:

$$
R\left(z^{-1}\right) \Delta u(k)=Z\left(z^{-1}\right) y_{r}(k)-S\left(z^{-1}\right) y(k),
$$

where $R\left(z^{-1}\right), S\left(z^{-1}\right)$ and $T\left(z^{-1}\right)$ are polynomials to be designed, to ensure that the system output $y(k)$ will tracks 
changes in the reference signal $y_{r}(k)$ in an acceptably fast way. Usually, it is required in steady state that the output $y(k)$ be equal to the reference setpoint (when $y_{r}(k)$ is constant). Therefore, this demands is satisfied with the polynomial $R\left(z^{-1}\right)$ equal to the unity.

The controller I+P (gray blocks) is shown in Figure 6.

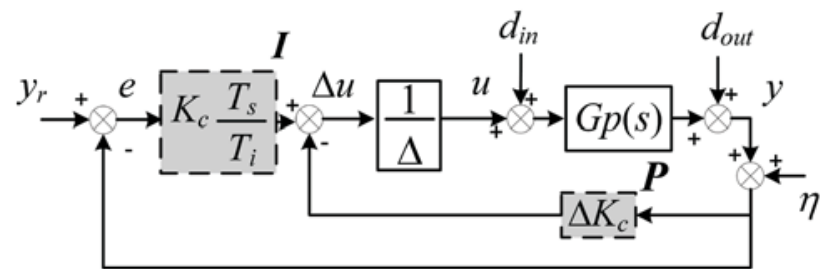

Fig. 6. I + P controller structure used in the system design procedure.

The Polynomials $R\left(z^{-1}\right)$ and $S\left(z^{-1}\right)$ given by,

$$
\begin{aligned}
& R\left(z^{-1}\right)=1 \\
& S\left(z^{-1}\right)=s_{0}+s_{1} z^{-1}, \\
& T\left(z^{-1}\right)=S\left(z^{-1}\right)
\end{aligned}
$$

where $s_{0}$, and $s_{1}$ are:

$$
\left\{\begin{array}{l}
s_{0}=K_{c}\left(1+\frac{T_{s}}{T_{i}}\right) \\
s_{1}=-K_{c}
\end{array}\right.
$$

One of the GPC criteria, which has been proposed by [17], is given by:

$$
J=E\left[\sum_{i=N_{1}}^{N_{y}}[y(k+1)-w(k)]^{2}+\lambda \sum_{i=1}^{N_{u}}[\Delta u(k+i-1)]^{2}\right]
$$

Where $\lambda$ denotes the control weighting factor, $w(k)$ the reference signal given by piecewise constants. Furthermore, the period from $N_{1}$ through $N_{y}$ denotes the prediction horizon, and $N_{u}$ denotes the control horizon. For simplicity, they are respectively set as $N_{1}=1, N_{y}=N$ and $N_{u}=N$, where $N$ is designed considering the time constant of the controlled object. Minimizing (28) yields the following control law [18]:

$$
\begin{aligned}
& \sum_{i=1}^{N} k_{i} F_{j}\left(z^{-1}\right) y(k)+\left\{1+z^{-1} \sum_{i=1}^{N} k_{i} G^{\prime} i\left(z^{-1}\right)\right\} \Delta u(k) \\
& -\sum_{i=1}^{N} k_{i} y_{r}(k)=0
\end{aligned}
$$

where $F_{j}\left(z^{-1)}\right.$ and $G_{j}\left(z^{-1}\right)$ are obtained by solving the following Diophantine equations:

$$
\begin{gathered}
1=E_{i}\left(z^{-1}\right) \Delta A\left(z^{-1}\right)+z^{-i} F_{i}\left(z^{-1}\right) \\
E_{j}\left(z^{-1}\right) B_{j}\left(z^{-1}\right)=R_{j}\left(z^{-1}\right)+z^{-1} S_{j}\left(z^{-1}\right),
\end{gathered}
$$

where:

$$
\left\{\begin{array}{l}
E_{i}\left(z^{-1}\right)=1+e_{1} z^{-1}+\ldots+e_{i-1} z^{-(i-1)} \\
F_{i}\left(z^{-1}\right)=f_{i, 0}+f_{i, 1} z^{-1}+\ldots+f_{i, n a} z^{-n a}
\end{array}\right.
$$

and the polynomials $R\left(z^{-1}\right), S\left(z^{-1}\right)$ and $T\left(z^{-1}\right)$ of GPC controller in RST are:

$$
\begin{aligned}
R\left(z^{-1}\right) & =\left[1+z^{-1} \sum_{i=1}^{N} G_{i}\left(z^{-1}\right)\right] \\
S\left(z^{-1}\right) & =\sum_{i=1}^{N} k_{i} F_{i}\left(z^{-1}\right) \\
T\left(z^{-1}\right) & =\sum_{i=1}^{N} k_{i}
\end{aligned}
$$

where $R\left(z^{-1}\right)$ is approximated by a static gain, $\nu$ defined:

$$
\nu=1+\sum_{i=N_{1}}^{N_{y}} k_{i} G_{i}(1) .
$$

Then, (29) can be rewritten as:

$$
\Delta u(k)=\frac{1}{\nu} \sum_{i=N_{1}}^{N_{y}} k_{i} y_{r}(k)-\frac{1}{\nu} \sum_{i=N_{1}}^{N_{y}} k_{i} F_{i}\left(z^{-1}\right) y(k)
$$

The simplified polynomials $\bar{R}\left(z^{-1}\right), \bar{S}\left(z^{-1}\right)$ and $\bar{T}\left(z^{-1}\right)$ of the GPC controller in RST are given by:

$$
\begin{aligned}
& \bar{R}\left(z^{-1}\right)=1 \\
& \bar{S}\left(z^{-1}\right)=\bar{s}_{0}+\bar{s}_{1} z^{-1} \\
& \bar{T}\left(z^{-1}\right)=\bar{t}_{0}
\end{aligned}
$$

where the coefficients $\bar{s}_{0}, \bar{s}_{1}$ and $\bar{t}_{0}$ are:

$$
\begin{aligned}
& \bar{s}_{0}=\frac{1}{\nu} \sum_{i=N_{1}}^{N_{y}} k_{i} f_{i, 0}, \\
& \bar{s}_{1}=\frac{1}{\nu} \sum_{i=N_{1}}^{N_{y}} k_{i} f_{i, 1}, \\
& \bar{t}_{0}=\frac{1}{\nu} \sum_{j=N_{1}}^{N_{y}} k_{j} .
\end{aligned}
$$

Finally, using (27) and (29), the parameters of the I+P controller are given by:

$$
\begin{aligned}
& K_{c}=-\bar{s}_{1} \\
& T_{i}=\frac{-\bar{s}_{1}}{\bar{s}_{0}+\bar{s}_{1}} T_{s}
\end{aligned}
$$

2) Structure of hybrid control using fuzzy logic - Using the proposed structure displayed in Figure 7, the action of two controllers can be mixed using the fuzzy logic. As it can be seen, there are two outputs for the fuzzy logic block. One goes directly to a multiplier block together with the $\mathrm{P}$ block output and the second output is a complementary fuzzy output and it is multiplied by the GPC block output. This complement is employed, since the fuzzy logic typically employs values ranging from zero to one.

By definition, the system error is the magnitude between the actual position and the reference position. The linguistic rules express the relationship between the input (errors) variables and they are expressed as: Positive Big (PB), Positive Medium (PM), Positive Small (PS), Zero (ZE), Negative Small (NS), Negative Medium (NM) and Negative Big (NB) errors. 


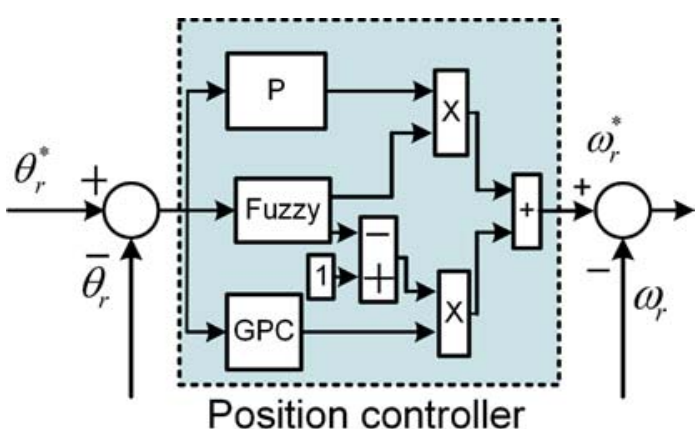

Fig. 7. Structure of the proposed hybrid position controller block based in fuzzy logic.

Table I shows the fuzzy rules used for the controller. As displayed, the behavior of the weighting fuzzy action applied to the P controller and the GPC controller, changes according to the position percentage error, e.g., when the position percentage error value is 0.45 , the fuzzy action will be of 0.3 and the weighting of the P and GPC controllers will be 0.3 and 0.7 , respectively, as shown in Figure 8.

TABLE I:

Fuzzy Rules Look-up Table

\begin{tabular}{cccc}
\hline $\begin{array}{c}\text { Position } \\
\text { error }\end{array}$ & $\begin{array}{c}\text { Fuzzy } \\
\text { action }\end{array}$ & $\begin{array}{c}\text { Proportional } \\
\text { controller } \\
\text { wieghting }\end{array}$ & $\begin{array}{c}\text { GPC } \\
\text { controller } \\
\text { weighting }\end{array}$ \\
\hline NB & PB & PB & PS \\
\hline NM & PM & PM & PS \\
\hline NS & PS & PS & PM \\
\hline ZE & ZE & ZE & PB \\
\hline PS & PS & PS & PM \\
\hline PM & PM & PM & PS \\
\hline PB & PB & PB & PS \\
\hline
\end{tabular}

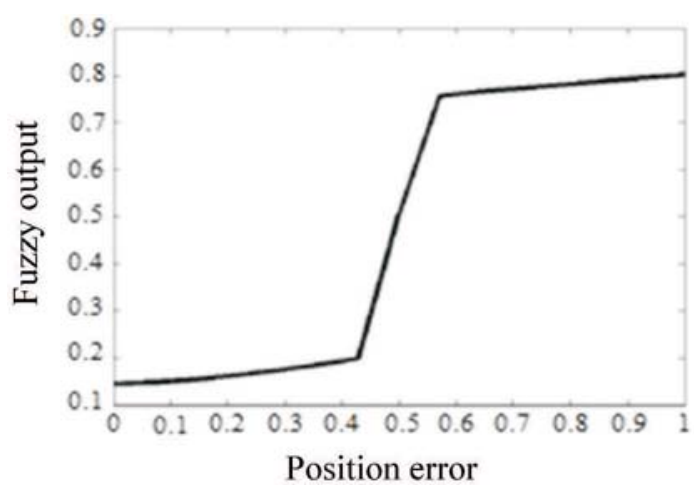

Fig. 8. Fuzzy control surface for the proper weighing of both controller.

In order to obtain the strategy mixing both controllers, three different regions are developed from the control surface, which are called SMALL, P-GPC, and LARGE, as shown in Figure 9, where $e$ is the normalized position error and $\mu$ is the membership degree.

The first strategy involves a pure GPC region with small relevance relation. The output of this region aims to keep the steady-state error in a minimum value or eliminate it. It is followed by a mixed region (P-GPC), which produces a single output controller. The purpose of this region is to smooth an eventual overshoot when the position reference is changed. The third and last area involves more the $\mathrm{P}$ action than the GPC action, and it is responsible to bring the system to the reference as fast as possible.

The structure of membership function can be adjusted empirically, which makes it more practical for the user, but it should have three regions for the hybridization to occur.

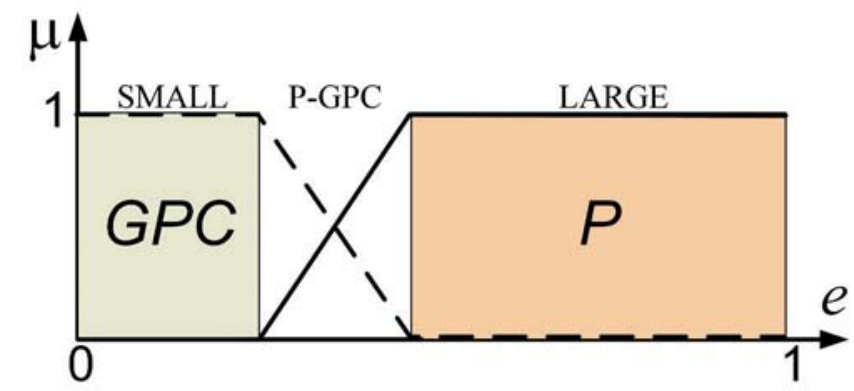

Fig. 9. Membership functions used in fuzzy logic for the proper weighing of both controller.

\section{SIMULATION AND EXPERIMENTAL RESULTS}

In order to simulate the position controller, the parameters are chosen as follow: $K_{p}=0.65477$ for the $\mathrm{P}$ controller and the GPC controller uses the user-specified parameters included in the proposed method, which are $N_{y}=10, N_{u}=$ $10, \lambda=0.1$ and $\nu=1$, resulting in the following parameters $t_{0}=0.1309, s_{1}=-0.1151$ and $s_{0}=0.2460$.

The fuzzy logic was used in order to mix the good results of $\mathrm{P}$ controllers, which act instantly when the reference is changed, with GPC controllers, which have a weighting in the steady-state time. The software MATLAB ${ }^{\mathrm{TM}}$ was used to adjust the suitable configuration for the fuzzy logic block. Thus, the fuzzy inference algorithm Mamdami and defuzzification method were chosen for the central area illustrated in Figure 9. The fuzzy block input is the normalized error between the reference position and the actual position of the rotor.

To further verify the validity of the implemented control strategy, several simulations of position control are described. Four types of reference signals were chosen: step, sinusoidal, trapezoidal and triangular. The step reference is to verify the controllerś performance for an abrupt change in the position reference. The sinusoidal reference is to verify the controllers performance when the position changes smoothly over the time. The trapezoidal reference is to verify the position tracking when the position increases linearly. The triangular reference verifies the abrupt position changing, when it reaches the maximum in either positive (or negative) direction.

\section{A. Simulation Results}

The reference position is stepwise changed to 3 radians at time $t=2 \mathrm{~s}$, as shown in Figure 10. The simulation 
results show a good transient control performance, taking around $\Delta t=1 \mathrm{~s}$ to stabilize. Figure 11 presents a reference trapezoidal profile. The position is increased linearly from $1 \mathrm{rad}$ at time $t=4 \mathrm{~s}$ in a ramp of $0.5 \mathrm{rad} / \mathrm{s}$. Then, the position is kept constant at time $t=6 \mathrm{~s}$ and returns to $1 \mathrm{rad}$ linearly at time $t=10 \mathrm{~s}$. The response for the triangular command is illustrated in Figure 12. At last, a periodic sinusoidal command was used, to control the rotor to move $\pm 1 \mathrm{rad}$ periodically. The rotor tracking response is shown in Figure 13. Figure 14 shows the response of the controller during a step in the load torque. The external torque with $0.2 \mathrm{Nm}$ was added at time $t=2 \mathrm{~s}$ and removed at $t=4 \mathrm{~s}$. An increase in the current $i_{q s}$ of -0.2 is shown in Figure 14. It is clear from the Figure 14 that the hybrid controller position kept the rotor at the reference position.

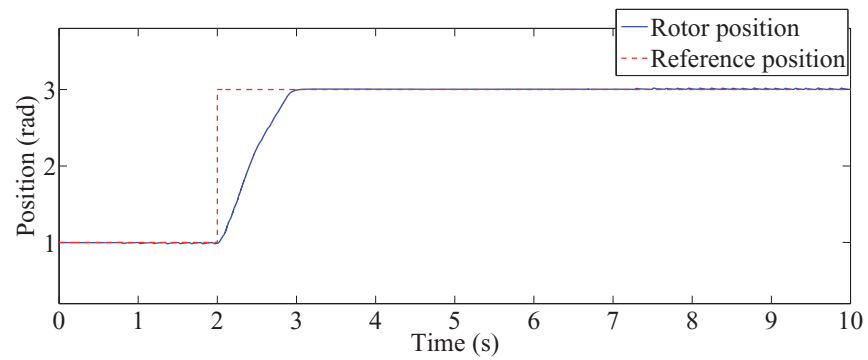

Fig. 10. Simulation results for the system using a step sign as reference.

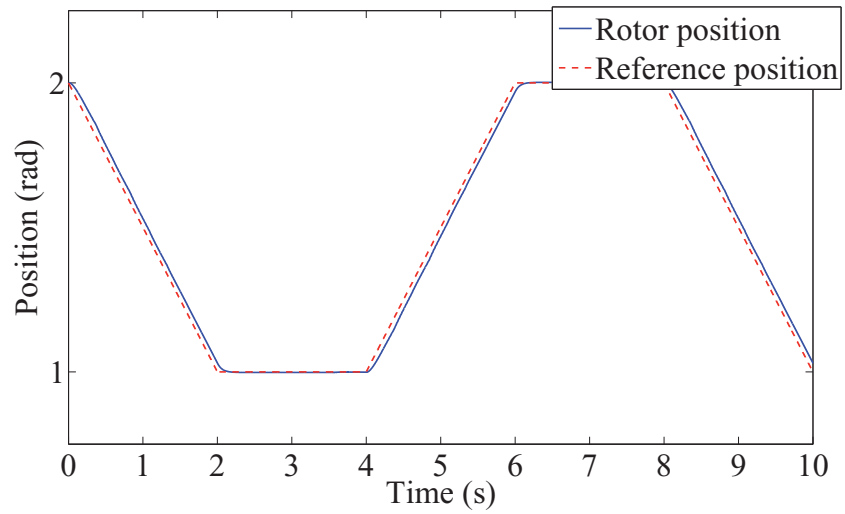

Fig. 11. Simulation results for the system using a trapezoidal sign as reference.

\section{B. Experimental Results}

In our experiments, the controller is carried out by a DSC from Texas Instruments ${ }^{\mathrm{TM}}$ TMS320F28335. The three-phase squirrel cage IM has four poles, $0.25 \mathrm{HP}$ and Y-connected windings. The specifications and parameters of the IM are given in Table II.

The schematics and one photo of experimental setup are shown in Figure 15 and 16. The inverter is a $1 \mathrm{kVA}$ industrial voltage-source three-phase inverter from Semikron ${ }^{\mathrm{TM}}$.

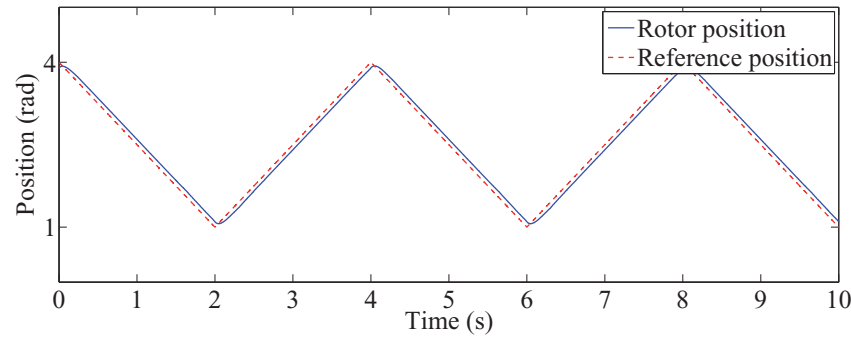

Fig. 12. Simulation results for the system using a triangular sign as reference.

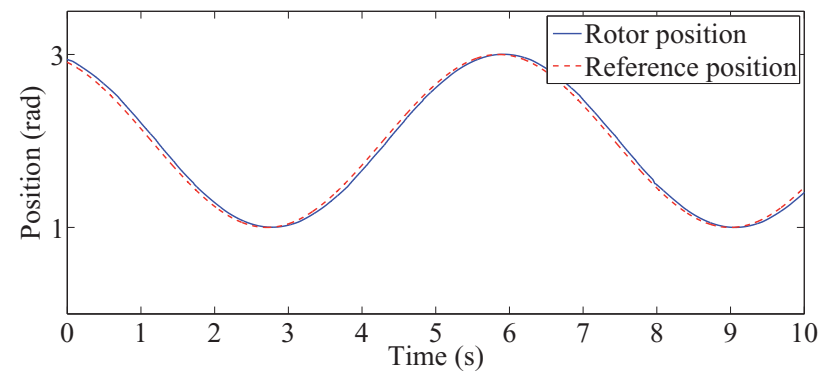

Fig. 13. Simulation results for the system using a sinusoidal sign as reference.
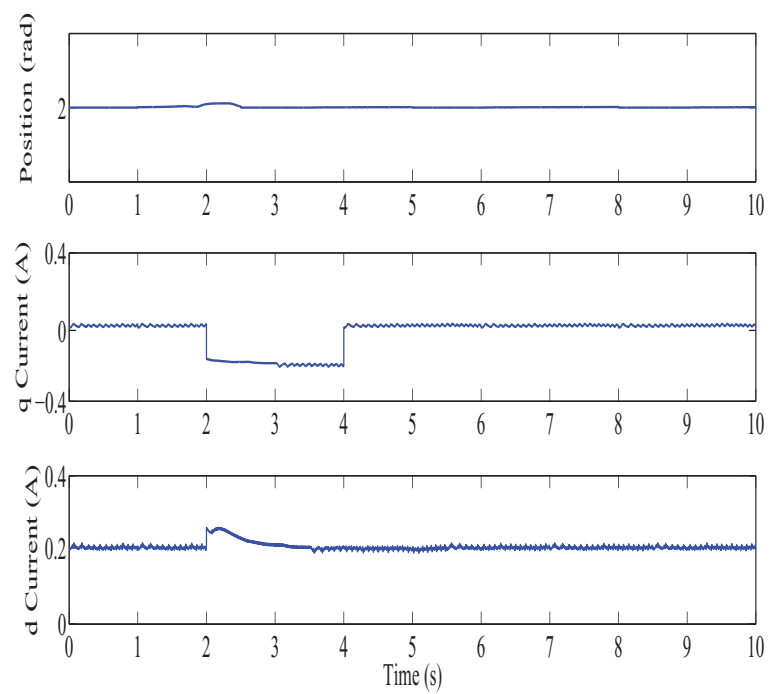

Fig. 14. Simulation results for the system with a two different conditions of load.

The mechanical load is a dc-motor from the manufacturer PHYWE ${ }^{\mathrm{TM}}$

The DSC produces a PWM switching frequency of $10 \mathrm{kHz}$ and the actual position is given by an incremental encoder, which is coupled to the motor shaft. The DSC is used to count the transients of the encoder signals and converts to radians. The sampling time is $0.1 \mathrm{~ms}$. The current sensors are Hall-effect current sensor from LEM $^{\mathrm{TM}}$.

The same control technique considered in the simulation tests was implemented for the experimental setup. 


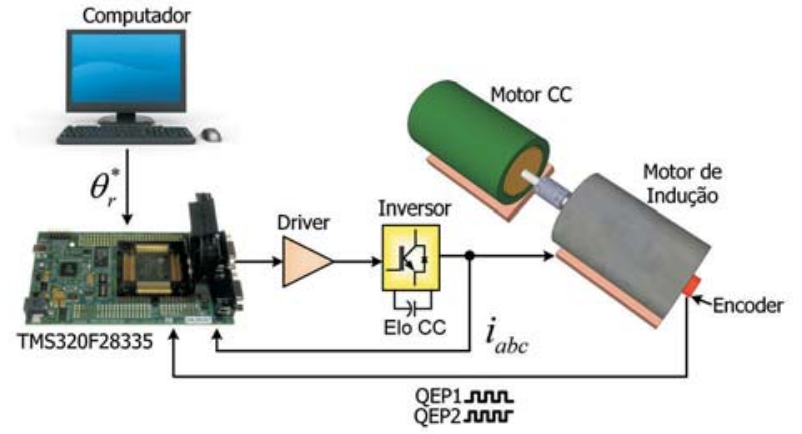

Fig. 15. Schematics of the proper systems interface among the main computer and the DSC.

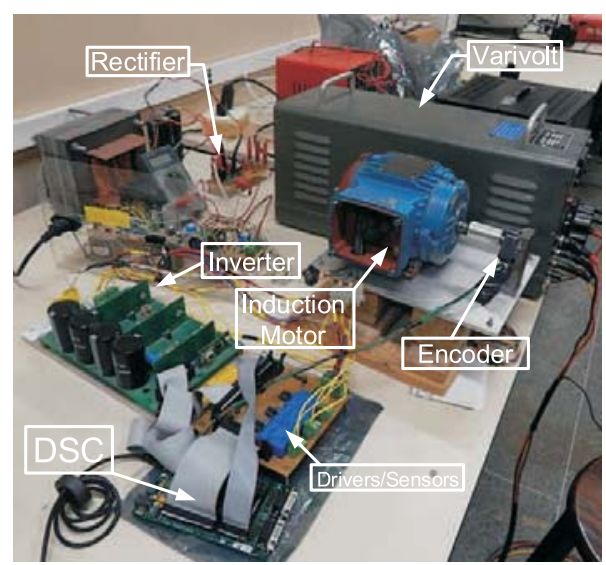

Fig. 16. Experimental setup for the system with the proposed control technique.

TABLE II:

Specification and parameters of the IM

\begin{tabular}{cc}
\hline \multicolumn{2}{c}{ Rated Specifications } \\
\hline Rated power & $0.25 \mathrm{HP}$ \\
\hline Rated speed & $1725 \mathrm{rpm}$ \\
\hline Rated voltage & $220 \mathrm{~V}$ \\
\hline Rated current & $1.26 \mathrm{~A}$ \\
\hline Number of poles & 4 \\
\hline \multicolumn{2}{c}{ Machine parameters } \\
\hline Rotor resistance $\left(R_{r}\right)$ & $87.44 \Omega$ \\
\hline Stator resistance $\left(R_{s}\right)$ & $35.58 \Omega$ \\
\hline Rotor Inductance $\left(L_{r}\right)$ & $0.16 \mathrm{H}$ \\
\hline Stator Inductance $\left(L_{s}\right)$ & $0.16 \mathrm{H}$ \\
\hline Mutual Inductance $\left(L_{m}\right)$ & $0.884 \mathrm{H}$ \\
\hline Inertia constant $(J)$ & $5 \cdot 10^{-4} \mathrm{~kg} \cdot \mathrm{m}^{2}$ \\
\hline Viscous friction coefficient $(B)$ & $5.65 \cdot 10^{-3} \mathrm{~kg} \cdot \mathrm{m}^{2} / \mathrm{s}$ \\
\hline
\end{tabular}

Figure 17 shows the measured response of the rotor position when a step reference was applied to the motor, where the step command is 3 radians. This is a no-load test and the rotor reaches the reference position at $\Delta t=3 \mathrm{~s}$.

In the results for the trapezoidal profile depicted in Figure 18 , the rotor tracked the reference with similar behavior observed in the simulations results. Moreover, the Figure 18 shows the current components $i_{d s}$ and $i_{q s}$.

Figure 19 shows the triangular test profile. The rotor follows the reference as expected. Therefore, we have shown the validity of the proposed controller for this tracking scenario. The detailed representation of the controlled currents is shown too.

The tracking performance of the rotor position due to the periodic sinusoidal reference trajectory at no-load condition is shown in Figure 20.

It is verified form Figures 17 to 20 that there is a oscillation in the results of $i_{q s}$ tracking profile. This characteristic is due to motor acts in standalone causing the rotating field oscillates more intensely and having the component related to the torque, $i_{q s}$, compensating this oscillation.

From the experimental results, the good model-following control performance is achieved by the proposed hybrid controller.
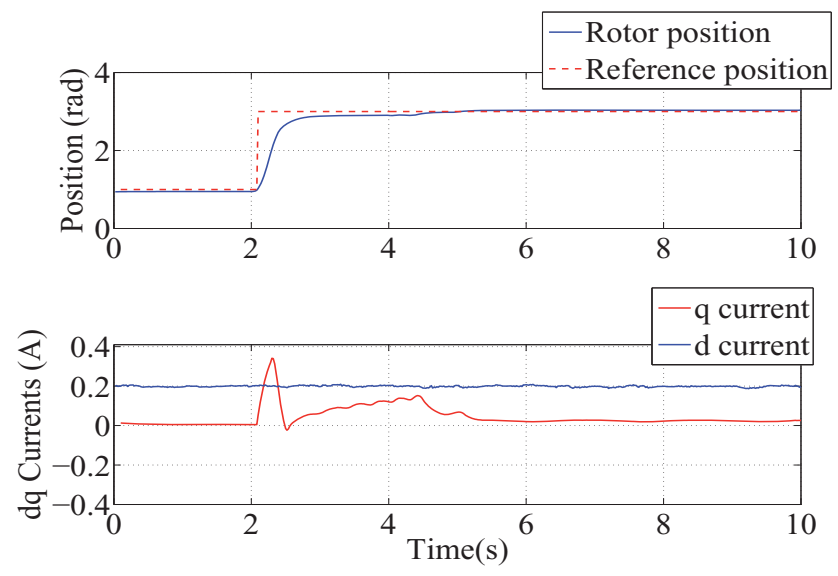

Fig. 17. Experimental results for the system using a step position reference.

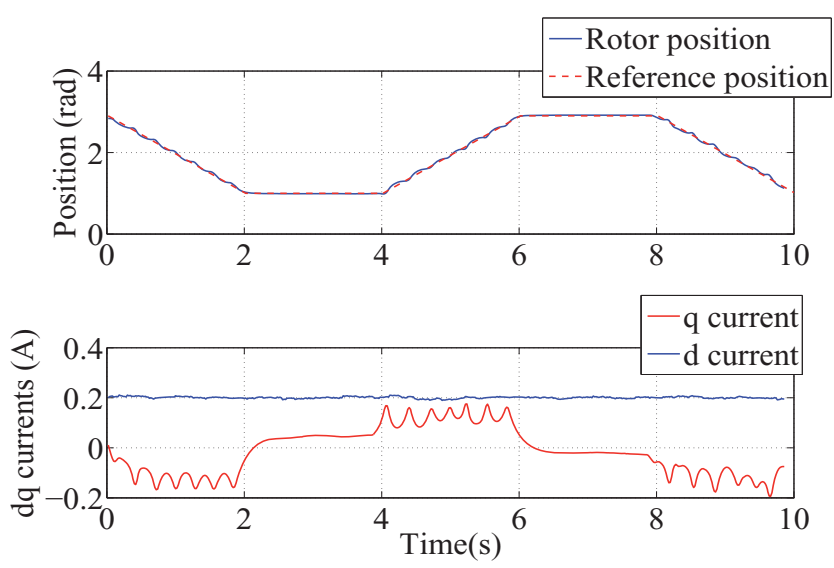

Fig. 18. Experimental results for the system using a trapezoidal reference.

Finally, Figure 21 shows the experimental result when a step change in the motor load from 0 to $0.2 \mathrm{Nm}$ is applied. The DC-motor was coupled to the rotor shaft, as shown in Figure 22.

When the load was applied the position had a small overshoot, as shown in the enlarged position of Figure 21. 

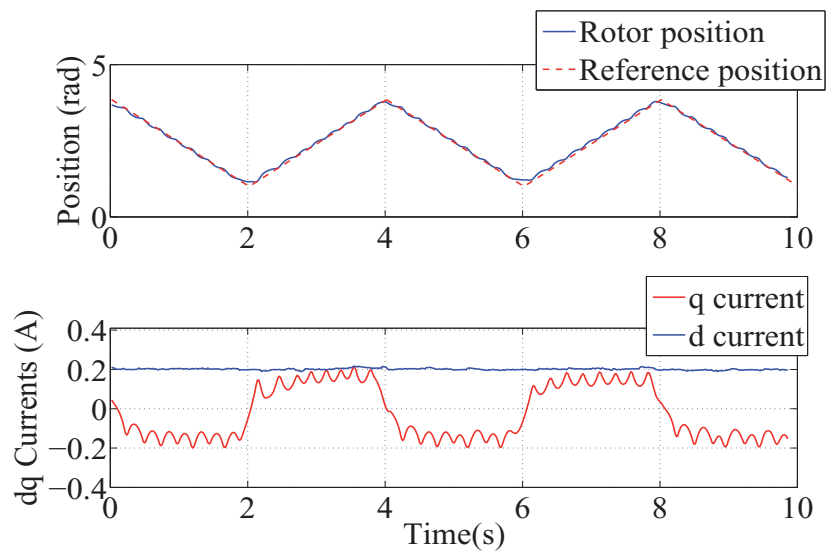

Fig. 19. Experimental results for the system using a triangular reference.
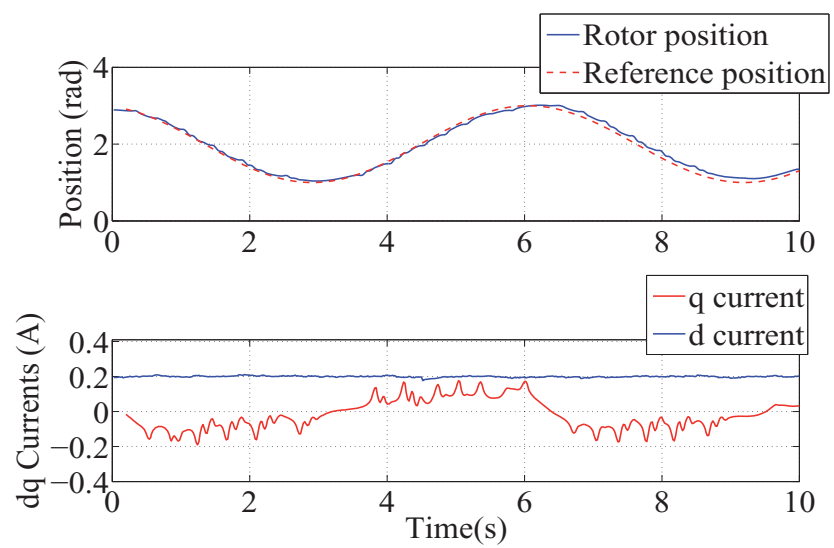

Fig. 20. Experimental results for the system using a sinusoidal position reference.

This result reveals that the hybrid controller is robust to external disturbances and it will apply a larger and fast torque command (increasing in the q-axis current component) in order to reduce the unknown disturbance. The load value was used to determine the initial behaviour of the proposed application and then be used in mechanical systems, such as a robotic arm actuator.

\section{CONCLUSION}

In this paper, it was illustrated the design and implementation of a hybrid position controller for an indirect fieldoriented induction motor drive. The fuzzy logic block weighs the P and GPC controllers actions in order to reach a exact and fast position tracking as well robustness. The settling time was about $1 \mathrm{~s}$ without any overshooting in the simulation and experimental results. The d-axis current remains in the constant reference value for the machine magnetizing and the q-axis current oscillates according to the position reference. Which is expected from the system modelling. Thus, the proposed technique has proven to fulfil the requirements for robotic applications, e.g., the motor drive located at the joint of a robotic arm.
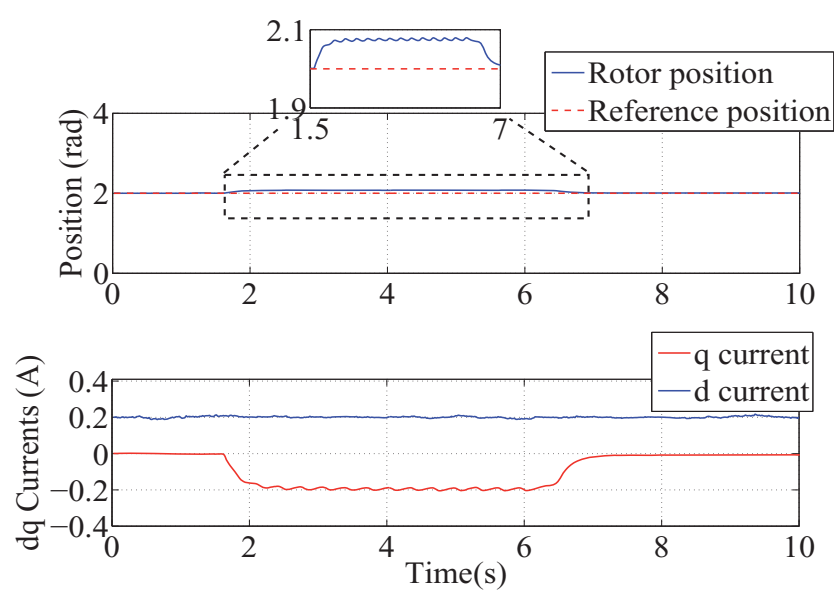

Fig. 21. Experimental results for the system when a load disturbance is applied.

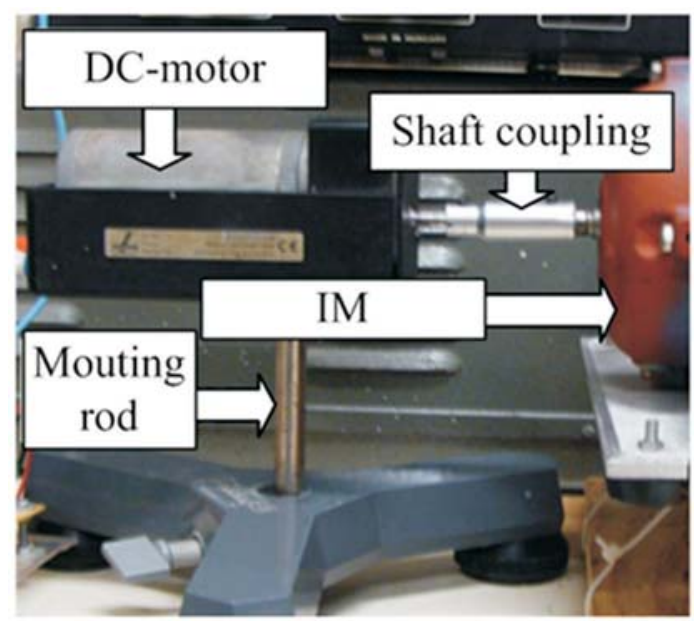

Fig. 22. DC-motor load coupled to the IM motor shaft for the disturbance tests.

\section{ACKNOWLEDGEMENT}

The authors acknowledge the Brazilian National Council for Research and Development $(\mathrm{CNPq})$ and Coordination of Improvement of Higher Education Personal (CAPES) for the financial support to this work.

\section{REFERENCES}

[1] B. K. Bose, Modern Power Electronics and AC Drives. Prentice-Hall PTR, 1st ed., 2001.

[2] Y.-Y. Tzou, "Dsp-based robust control of an ac induction servo drive for motion control," IEEE Transactions on Control Systems Technology, vol. 4, pp. 614-626, Nov 1996.

[3] J. L. Azcue-Puma, A. J. S. Filho, and E. Ruppert, "Direct vector control with fuzzy currente controller for three-phase induction motor.," Eletrônica de PotênciaSOBRAEP, vol. 18, pp. 917-925, 2013. 
[4] V. P. Pinto, J. C. T. Campos, N. Rocha, and C. B. Jacobina, "Controlador robusto multivareável com ação integral aplicado em um sistemade geração eólica," Eletrônica de Potência-SOBRAEP, vol. 63, pp. 147157, Jan 2011.

[5] E. de C. Diniz, A. B. de Souza Júnior, D. de A. Honório, L. H. S. C. Barreto, and L. L. N. dos Reis, "Sliding mode control for current loop in an induction motor apllied to a robot arm.," Eletrônica de PotênciaSOBRAEP, vol. 17, pp. 671-680, Feb 2012.

[6] E. de Santana, E. Bim, and W. do Amaral, "A predictive algorithm for controlling speed and rotor flux of induction motor," IEEE Transactions on Industrial Electronics, vol. 55, pp. 4398-4407, Dec 2008.

[7] C. B. Jacobina, L. A. de S. Ribeiro, J. B. de M. Filho, F. Salvadori, and A. M. N. Lima, "Sistema de acionamento com motor de indução orientado indiretamente pelo campo com adaptação mrac da velocidade.," Revista Controle \& Automação, vol. 14, pp. 41-49, Ago 2003.

[8] J. Thomas and A. Hansson, "Speed tracking of a linear induction motor-enumerative nonlinear model predictive control," IEEE Transactions on Control Systems Technology, vol. 21, pp. 1956-1962, Sept 2013.

[9] T.-J. Ho and L.-Y. Yeh, "Design of a hybrid pid plus fuzzy controller for speed control of induction motors," in Proc. of Industrial Electronics and Applications (ICIEA), 2010 the 5th IEEE Conference on, pp. 13521357, June 2010.

[10] K. Halbaoui, D. Boukhetala, and F. Boudjema, "New robust model reference adaptive control for induction motor drives using a hybrid controller," in Proc. of Power Electronics, Electrical Drives, Automation and Motion, 2008. SPEEDAM 2008. International Symposium on, pp. 1109-1113, June 2008.

[11] P. Egiguren and B. Oscar, "Robust position control of induction motor drives," in Proc. of Industrial Electronics (ISIE), 2010 IEEE International Symposium on, pp. 1468-1473, July 2010.

[12] C.-Y. Wan, S.-C. Kim, and B. Bose, "Robust position control of induction motor using fuzzy logic control," in Proc. of Industry Applications Society Annual Meeting, 1992., Conference Record of the 1992 IEEE, pp. 472481 vol.1, Oct 1992.

[13] A. A. R. Coelho and L. S. Coelho, Identificação de sistemas dinâmicos lineares. Editora UFSC, 1st ed., 2004.

[14] M. Yuwana and D. E. Seborg, "A new method for online controller tuning.," AIChE J., vol. 3, pp. 434-440, 1982.

[15] L. A. Aguirre, Introdução à Identificação de Sistemas. Editora UFMG, 1st ed., 2004.

[16] K. Aström and T. Hägglund, PID Controlers: Theory, Design and Tunning. Instrument Society of America, 1995.

[17] D. Clarke, "Generalized predictive control: A robust self-tuning algorithm," in Proc. of American Control Conference, 1987, pp. 990-995, June 1987.

[18] F. Camacho and C. Bordons, Model Predictive Control. Spring, 1st ed., 2004.

\section{BIOGRAPHIES}

Antonio Barbosa de Souza Júnior was born in Fortaleza in 1984. He received the B.Sc. degree in Control and Automation Engineering from the University of Fortaleza, Fortaleza, Brazil in 2007, and also the M.Sc. degree in Electrical Engineering from the Federal University of Ceará, Fortaleza, Brazil in 2010. Currently he is $\mathrm{PhD}$ student at the Federal University of Ceará. His interest areas are Electrical Machines Drives, Power Electronics, Vector Control, and Robotics.

Tobias Rafael Fernandes Neto was born in Fortaleza, Brazil, in 1981. He received the bachelor degree in electrical engineering from the Fortaleza University, Fortaleza, Brazil, in 2004, the master degree (M.Sc.) in electrical engineering from Federal University of Ceará, Fortaleza, Brazil, in 2007 and the Dr.-Ing. degree. in electrical engineering from Darmstadt University of Technology, Darmstadt, Germany, in 2012.

Dalton de Araújo Honório was born in Fortaleza, Brazil, in 1988. He received the B.Sc. degree in Electrical Engineering from the Federal University of Ceará, Fortaleza, Brazil, in 2010 and the master degree (M.Sc.) in electrical engineering from Federal University of Ceará. He is currently pursuing the $\mathrm{PhD}$ degree in Electrical Engineering at the same university and, acting as a researcher for CAPES at the same institution, working on the development of AC machine drive for robotic applications and Modular Multilevel Converter.

Eber de Castro Diniz was born in Salvador, Brazil, in 1977. He received the B.Sc. degree in electrical engineering from the Federal University of Ceará, Fortaleza, Brazil, in 2003 and the B.Sc. degree in electrical engineering in 2006 from the same university. He currently serves as assistant professor at the Federal University of Ceaá, Sobral, Brazil at the Department of Electrical Engineering. His areas of interest are Predictive Control, Optimal Control, Robust Control, Electrical Machines, Power Electronics, Embedded Systems, Control applied to Power Generation, and Vector Control.

Luiz Henrique Silva Colado Barreto was born in Navirai, Brazil. He received the B.S. degree in Electrical Engineering from the Federal University of Mato Grosso, Cuiaá, Brazil, in 1997, and the M.S. and Ph.D. degrees from the Federal University of Uberlandia, Uberlandia, Brazil, in 1999 and 2003, respectively. Since June 2003, he has been with the Department of Electrical Engineering, Federal University of Ceará, Fortaleza, Brazil, where he is currently a Professor with the Department of Electrical Engineering. His research interests include high-frequency power conversion, modeling and control of converters, power factor correction circuits, new converter topologies, uninterruptible power system systems, and fuel cells.

Laurinda Lúcia Nogueira dos Reis received the B.Sc. degree in Electrical Engineering from the Federal University 
of Ceaá, Fortaleza, Brazil in 1979, and the M.Sc. degree in Electrical Engineering from the Federal University of Paraíba, Campina Grande, Brazil in 1984, respectively. She obtained the Ph.D. degree degree in Electrical Engineering from the Federal University of Santa Catarina, Florianópolis, Brazil in 2008. She has been a professor with the Federal
University of Ceará, Fortaleza, Brazil since 1979. Her research interest areas are electric machinery, electric machine drives, advanced techniques for electromechanical systems, and nonlinear systems. 